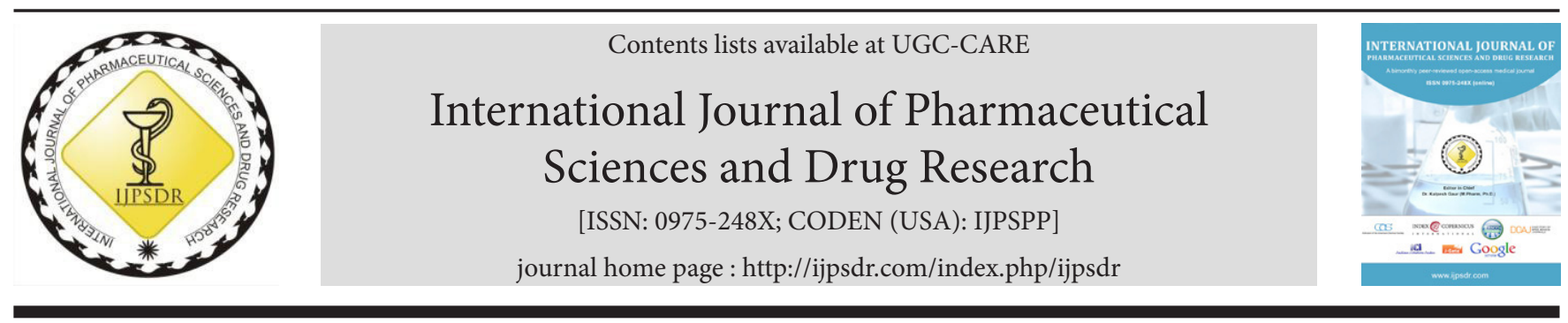

Research Article

\title{
In vitro Antidiabetic Activity by Glucose Uptake of Yeast Cell Assay and Antioxidant Potential of Annona Reticulata L. Leaf Extracts
}

\author{
Vineela Pulivarthi ${ }^{1}$, Penchalaneni Josthna ${ }^{2}$, Challagundla Varadarajulu Naidu ${ }^{{ }^{*}}$ \\ ${ }^{1}$ Department of Biotechnology, School of Herbal Studies and Naturo Sciences, Dravidian University, Kuppam-517426, Andhra Pradesh, India \\ ${ }^{2}$ Department of Biotechnology, Sri Padmavathi Mahila Visvavidyalam, Tirupati-517502, Andhra Pradesh, India
}

\begin{tabular}{l} 
A R T I C L E I N F O \\
\hline Article history: \\
Received: 13 December, 2019 \\
Revised: 05 April, 2020 \\
Accepted: 20 April, 2020 \\
Published: 30 May, 2020 \\
Keywords: \\
Annona reticulata L., \\
Antioxidant, \\
Antidiabetic, \\
DPPH, \\
Glucose uptake. \\
DOI: \\
10.25004/IJPSDR.2020.120301
\end{tabular}

\section{INTRODUCTION}

There is an assortment of evidence showing that exorbitant liberation of free radicals and lipid peroxidation are effectively associated with the pathogenesis of a wide range of ailments, which includes cardiovascular and cerebral ischemia, atherosclerosis, diabetes, carcinogenesis, rheumatic disorders, etc. ${ }^{[1]}$ Among them, diabetes mellitus (DM) is considered as a 7th leading source of death in 2030 as perWHO (World Health Organization) reports. ${ }^{[2]}$ The defective insulin action or insulin secretion ensue the rise of blood glucose levels in the body by hampering the uptake of glucose into the cells leading to a variety of

\begin{abstract}
A B S T R A C T
The undesirable adverse effects of present available synthetic drugs endorse modern medicine to search for the superior choice for the treatment of metabolic diseases. Herbal medicine turns out to be a hopeful therapy for the effective treatment of diabetes in the foreseeable future. In an effort to render scientific evidence for the antidiabetic potential of Annona reticulata L., the present research, with the objective to evaluate the ability of $A$. reticulata leaf extracts on anti-hyperglycemic property under in vitro using yeast cell model was performed. Besides, as diabetes and its complications are highly associated with oxidative stress, the current study was also focused on the antioxidant property of A. reticulata leaf extracts. The scavenging ability of plant extracts on free radical 2,2-diphenyl-1-picrylhydrazyl (DPPH), ferric reducing power assay, and total antioxidant activity was performed to establish the antioxidant by the glucose uptake method using the yeast cell model. Among the four chosen solvent extracts- aqueous, methanol, ethyl acetate, $n$-hexane, and methanol extract (MeE) exhibited high antioxidant potential. MeE exhibited $62.28 \%$ of DPPH inhibition at $200 \mu \mathrm{g} / \mathrm{mL}$, with total antioxidant activity $164.72 \pm 2.63 \mu \mathrm{g} / \mathrm{mL}$ and higher absorbance in reducing power assay $(1.15 \pm 0.03)$. In vitro antidiabetic activity by glucose uptake of yeast cell assay was evaluated and observed dose-dependent rise in \% of glucose uptake in methanol, ethyl acetate, and aqueous extracts of A. reticulata. MeE showed $48.55 \%$ of glucose uptake at $500 \mu \mathrm{g} / \mathrm{mL}$ concentration. Hence, the present study could be concluded as A. reticulata leaves possess potent antioxidant activity and antidiabetic activity under in vitro conditions. With the outcome of the present initial study, research work could be extended further; thereby, the exact pharmacological action of the plant compounds could be discovered.
\end{abstract}

\footnotetext{
${ }^{*}$ Corresponding Author: Prof. Challagundla Varadarajulu Naidu

Address: School of Herbal Studies and Naturo Sciences, Department of Biotechnology, Dravidian University, Kuppam-517426, Andhra Pradesh, India Email $\bowtie$ : challagundlav@yahoo.co.in

Tel.: +91-9949632093

Relevant conflicts of interest/financial disclosures: The authors declare that the research was conducted in the absence of any commercial or financial relationships that could be construed as a potential conflict of interest.

Copyright (C) 2020 Vineela Pulivarthi et al. This is an open access article distributed under the terms of the Creative Commons AttributionNonCommercial-ShareAlike 4.0 International License which allows others to remix, tweak, and build upon the work non-commercially, as long as the author is credited and the new creations are licensed under the identical terms.
}

complications. ${ }^{[3]}$ There is increasing evidence that diabetes is closely linked with several metabolic abnormalities; one among them is oxidative stress caused by reactive molecular species. ${ }^{[4]}$ Free radicals are reactive molecular species indulged in numerous physiological processes that are produced naturally in the body via the metabolism of carbohydrates, proteins, fats, etc. ${ }^{[5,6]}$ The generated free radicals commonly in the body are $02^{--}, \cdot-\mathrm{OH},{ }^{1} \mathrm{O}_{2}$, $\mathrm{NO}^{-}, \mathrm{RO}_{2}{ }^{-}$, and ${ }^{-} \mathrm{ONOO}$. The disparity occurred between the synthesis of reactive molecular species, and their neutralization leads to the accumulation of numerous free radicals. ${ }^{[7]}$ The natural defense system of our body purges 
free radicals from time to time, facilitated by antioxidant enzymes and antioxidant molecules. ${ }^{[8]}$ During diabetes, the persistence of hyperglycaemic condition in the body induces the oxidative stress by generating reactive oxygen species (ROS), which leads to lipid peroxidation and thus, injures the cells, damages the tissues and dysfunctions the organs, eventually leads to the secondary complications, i.e., diabetic retinopathy, nephropathy, neuropathy, and cardiovascular diseases. ${ }^{[9,10]}$ The glucose oxidation, protein glycosylation during hyperglycemia exaggerates the production of ROS. The depletion of endogenous antioxidants and natural, free radical scavengers were observed in hyperglycemic conditions. ${ }^{[1]}$ Antioxidant compounds are chemical in nature that effectively hampers or delays the oxidation of the biomolecules by binding to the free oxygen radicals, and thus, protects the cells and tissues from the oxidative attacks. ${ }^{[5]}$ The antioxidant activity of antioxidants is mainly conferred by their redox property, which has a key role in quenching the oxygen species, decomposing the peroxides, neutralizing, or adsorbing free radicals. ${ }^{[12]}$ The available commercial antioxidants were restricted as they are suspected of possessing some toxic carcinogens, which may cause cancer and liver damage. ${ }^{[13]}$ In this regard, there is a high quest to explore natural compounds with free radical scavenging or antioxidant activity. Numerous studies have stated that the natural active constituents present in the plant were reported to have radical scavenging and antioxidant activities. ${ }^{[14]}$ Evaluating the antioxidant potential helps to investigate the ameliorating ability of natural drug compounds on the anti-hyperglycemic property associated with oxidative stress.

To discover the therapeutic potential of various natural active compounds of the plant with antioxidant and antidiabetic activities, our study was conducted on the leaves of $A$. reticulata L., belongs to family Annonaceae, frequently known as Ramphal, is a traditional medicinal plant generally distributed in subtropical and humid regions. The leaves of $A$. reticulata are copious in phytochemicals such as phenolics, glycosides, flavonoids, steroids, proteins, tannins, alkaloids, etc. ${ }^{[15]}$ Many studies have stated that these phytochemicals possess various pharmacological activities that involve in alleviating the dreadful ailments as they possess anticancer, antidiabetic, antioxidant, and antimicrobial properties. ${ }^{[16]}$ It was reported that $A$. reticulata was traditionally employed to treat cardiac problems, ulcer, bacterial infection, epilepsy, dysuria, etc. ${ }^{[15]}$ Researchers Kadali and Sandeep ${ }^{[17]}$ surveyed and reported that traditional healers of West Godavari district of Andhra Pradesh, use the decoction of $A$. reticulata leaves to treat diabetes, but the need for scientific evidence in proper usage of the natural plant compounds is highly required to employ them for their pharmacological activities. Research findings on evaluating the potential of medicinal plants bestow a boon to human health. The adverse effects or complications on the usage of synthetic drugs might be diminutive with the scientific assessment of herbal medicine. Nasri et al. ${ }^{[18]}$ summarized several medicinal plants that possess hypoglycaemic properties. Research on Galega officinalis, a medicinal plant, yielded an antidiabetic drug known as "metformin." ${ }^{[19]}$ WHO recognized the significance of herbal medicine to treat various ailments and included metformin, a plant-derived antidiabetic drug in essential medicine's list for treatment of type2 diabetes mellitus (T2DM). Therefore, search of natural compounds to cure the diseases as therapeutic agents with less adverse effects triumphs attention globally. In pursuit of this, the present study was focussed on free radical scavenging and antidiabetic activity of $A$. reticulata leaves, which might reveal its potential as traditional herbal medicine and might aid in treating diabetes with no or minimal side effects. With the evidence of the presence of phytochemicals, the antioxidant potential and antidiabetic activity of $A$. reticulata leaf extracts by glucose uptake of yeast cells assay under in vitro was evaluated.

\section{Materials AND Methods}

\section{Plant Leaf Collection}

Fresh leaf samples of $A$. reticulata were gathered from the surroundings of Dravidian University, Kuppam, Andhra Pradesh during the period May to June 2017. Herbarium specimen (voucher no. 0652, dated June 2017) was authenticated and deposited for reference in Botany Department, S. V. University, Tirupati, Andhra Pradesh, India. Fig. 1(a) was the $A$. reticulata L. (Ramaphal) plant, and Fig. 1(b) was the leaves of $A$. reticulata.

\section{Chemicals}

2,2-diphenyl-1-picrylhydrazyl (DPPH), ammonium molybdate, sulphuric acid, sodium phosphate, trichloroacetic acid (TCA), potassium ferricyanide $\left(\mathrm{C}_{6} \mathrm{~N}_{6} \mathrm{FeK}_{3}\right)$, disodium hydrogen phosphate, sodium dihydrogen phosphate, sodium hydroxide, hydrochloric acid, ferric chloride, metronidazole (MTZ), and ascorbic acid. All the analytical grade chemicals were purchased commercially from local vendors.

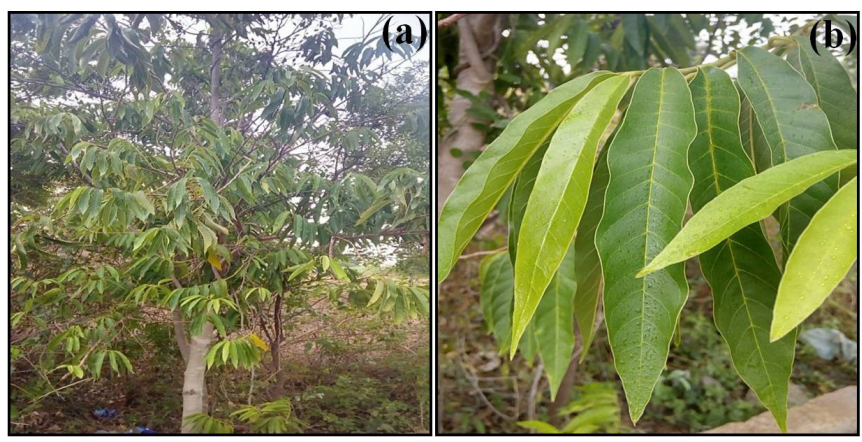

Fig. 1(a): Annona reticulata L. whole plant
Fig. 1(b): Leaves of Annona reticulata $\mathrm{L}$. 


\section{Sample Preparation}

The leaf samples were dried under shade at room temperature $\left(25 \pm 5^{\circ} \mathrm{C}\right)$ for ten days and were powdered, extracted with four solvents, i.e., aqueous, ethyl acetate, methanol, and n-hexane by using soxhlet apparatus. The extracts later were concentrated to dryness using a rotary evaporator to obtain semi-dried solid masses. The extracts were tightly packed and stored at $4^{\circ} \mathrm{C}$ for further use.

\section{In vitro Antioxidant Assays}

\section{DPPH Assay}

The free radical DPPH scavenging potential of the four extracts was determined by using the stable DPPH method. ${ }^{[20]}$ Each extract was prepared at five different concentrations ( 25 to $200 \mu \mathrm{g} / \mathrm{mL}$ ). $4 \mathrm{~mL}$ of $0.1 \mathrm{mM} \mathrm{DPPH}$ solution was added to the $1 \mathrm{~mL}$ of sample solution of different concentrations. After 30 minutes of incubation, the absorbance was recorded using ELICO SL210 UV double beam spectrophotometer at $517 \mathrm{~nm}$. Synthetic antioxidant ascorbic acid at the same concentrations ( 25 to $200 \mu \mathrm{g} / \mathrm{mL}$ ) was used as a standard control, and the solution without extract/ standard was considered as a blank. The lower the absorbance of the samples, the higher the DPPH scavenging activity. The $\mathrm{IC}_{50}$ value for each extract was calculated by plotting a standard curve.

$$
\begin{aligned}
& \% \text { inhibition of DPPH radical }=\frac{\text { AbsControl }- \text { AbsSample }}{\text { AbsControl }} \times 100 \\
& \text { Where Abs = absorbance. }
\end{aligned}
$$

\section{Total Antioxidant Activity}

The total antioxidant activity of samples was assessed by phosphomolybdenum method. ${ }^{[20]}$ The reagent was freshly prepared $(4 \mathrm{mM}$ ammonium molybdate, $0.6 \mathrm{M}$ $\mathrm{H}_{2} \mathrm{SO}_{4}, 28 \mathrm{mM} \mathrm{Na}_{3} \mathrm{PO}_{4}$ ). $2 \mathrm{~mL}$ of reagent was added to the ascorbic acid standard ( 25 to $200 \mu \mathrm{g} / \mathrm{mL}$ ) and $1 \mathrm{~mL}$ of plant extracts $(1 \mathrm{mg} / \mathrm{mL})$, followed by incubation at $95^{\circ} \mathrm{C}$ for 90 minutes. A green phosphomolybdenum complex was formed. After cooling down the temperature, the absorbance was assessed at $695 \mathrm{~nm}$. Reagent solution without any standard or extract acts as a blank. The antioxidant activity was calculated by plotting the ascorbic acid standard curve. The test was carried out in triplicates.

\section{Reducing Power Assay}

The reduction capacity of ferric $\left(\mathrm{Fe}^{3+}\right)$ to ferrous $\left(\mathrm{Fe}^{2+}\right)$ ions by the plant extracts was analyzed. ${ }^{[8]} 1 \mathrm{~mL}$ of each extract/ standard was taken in the concentration range of 25 to $200 \mu \mathrm{g} / \mathrm{mL} .2 .5 \mathrm{~mL}$ of $0.2 \mathrm{M} \mathrm{PO}_{4}{ }^{2-}$ buffer (pH 6.6), $2.5 \mathrm{~mL}$ of $1 \% \mathrm{C}_{6} \mathrm{~N}_{6} \mathrm{FeK}_{3}$ were mixed. The entire solution was allowed to stand still for 20 minutes incubation at $50^{\circ} \mathrm{C}$ in a water bath. Later $10 \%$ trichloroacetic acid (TCA) was added to the solution, followed by centrifugation at $5,000 \mathrm{rpm}$ for 10 minutes. $2.5 \mathrm{~mL}$ of the top layer of the mixture was collected and mixed with the $2.5 \mathrm{~mL}$ of water and freshly prepared $0.5 \mathrm{~mL}$ of $0.1 \% \mathrm{FeCl}_{3}$. The entire solution was mixed well, and allowed for 10 minutes of incubation. The ferrous ion complex that was formed at the end of the experiment was in Perl's Prussian blue color. The absorbance was noted at $700 \mathrm{~nm}$ by using a UV double beam spectrophotometer. As a standard control, ascorbic acid was used. The higher absorbance of the samples implies the elevated reducing power.

\section{In vitro Antidiabetic Activity}

\section{Determination of In vitro Antidiabetic Activity by Glucose Uptake in Yeast Cell Model}

The distinct method of Shettar et al. ${ }^{[2]}$ was followed to determine the glucose uptake in yeast cells. $1 \%$ suspension of commercially available baker's yeast (Saccharomyces cerevisiae) cells was set at $25^{\circ} \mathrm{C}$. The overnight yeast cell suspension was centrifuged (4,200 rpm for 5 minutes) again and again until the clear supernatant fluid was obtained. With the clear supernatant, about $10 \% \mathrm{v} / \mathrm{v}$ yeast cell suspension was made ready for the experiment. The plant samples, the standard drug (MTZ) at various concentrations 100 to $500 \mu \mathrm{g} / \mathrm{mL}$ were mixed to $1 \mathrm{~mL}$ of $10 \mathrm{mM}$ glucose solution and allowed for 10 minutes incubation at $37^{\circ} \mathrm{C}$. The reaction was initiated after adding $100 \mu \mathrm{L}$ of yeast suspension to the mixture, followed by vortex and incubation for 60 minutes, at $37^{\circ} \mathrm{C}$. Later the samples were centrifuged at 3,800 rpm for 5 minutes. The amount of glucose was estimated in the supernatant by a UV-vis spectrophotometer at $520 \mathrm{~nm}^{[4]}$. The control sample contains all the reagents except the test sample. The whole experiment was performed in triplicates.

The percentage of glucose uptake was calculated by the formula

$$
\% \text { of glucose uptake }=\frac{\text { AbsControl }- \text { AbsSample }}{\text { AbsControl }} \times 100
$$

Where Abs $=$ absorbance.

\section{Statistical Analysis}

All experiments were carried out in three independent analyses and indicated as mean \pm standard deviation (SD). Comparisons were analyzed by ANOVA using Post-Hoc Tukey multiple comparison test in SPSS 16 software. $p<0.001$ was taken as significant.

\section{RESULTS}

\section{In vitro Antioxidant Assays}

\section{DPPH Assay}

The ability of the reduction of free radical DPPH was evaluated for all the four extracts. All the extracts showed the inhibition in a dose-dependent way in the range of concentrations 25 to $200 \mu \mathrm{g} / \mathrm{mL}$. The $\mathrm{IC}_{50}$ value is the amount of antioxidants present in the sample that is required to inhibit the free radicals by $50 \%$. Lower the $\mathrm{IC}_{50}$ value, the higher is the radical scavenging ability. Among 
all the extracts the MeE showed the better activity in a dose-dependent manner with the maximum inhibition of $62.28 \%$ at $200 \mu \mathrm{g} / \mathrm{mL}$ and $\mathrm{IC}_{50}$ value of $149.14 \pm 6.1 \mu \mathrm{g} / \mathrm{mL}$, whereas, the positive standard ascorbic acid showed the $84.53 \%$ inhibition and $\mathrm{IC}_{50}$ value at $57.85 \pm 4.3 \mu \mathrm{g} / \mathrm{mL}$. The order of the extracts with the higher scavenging activity to lower is $\mathrm{MeE}>\mathrm{EaE}>\mathrm{AqE}>\mathrm{nhE}$. The $\mathrm{IC}_{50}$ values and \% of inhibition at $200 \mu \mathrm{g} / \mathrm{mL}$ of the extracts were detailed in Table 1 . The $\%$ inhibition shown by the $A$. reticulata leaf extracts on DPPH scavenge activity was depicted in Fig. 2.

\section{Total Antioxidant Activity}

The phosphomolybdenum assay showed the total antioxidant activity of all the extracts. The antioxidant activity of the extracts was assessed from the linear regression equation of the standard curve with $y=0.012 x$ $-0.015, R^{2}=0.967$. The ability to reduce the ion Mo (VI) to Mo (V) was shown higher in the MeE than the other extracts. The standard ascorbic acid graph was shown in

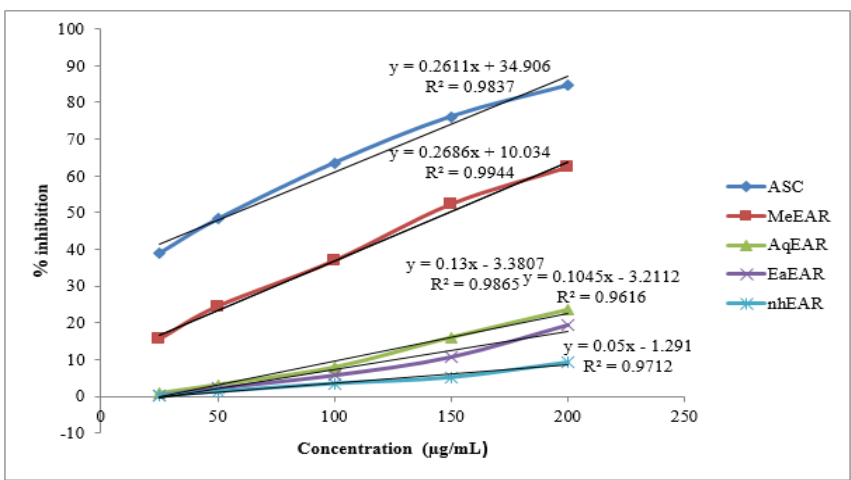

Fig. 2: DPPH scavenging activity of $A$. reticulata leaf extracts represented the \% inhibition of DPPH radicals by $A$. reticulata leaf extracts; $\mathrm{Asc}=$ ascorbic acid; $\mathrm{MeE}=$ methanolic extract; $\mathrm{AqE}=$ aqueous extract; $\mathrm{EaE}=$ ethyl acetate extract; $\mathrm{nhE}=\mathrm{n}$-hexane extract

Table 1: DPPH scavenging activity of all the four extracts of A. reticulata leaves

\begin{tabular}{lll}
\hline & $\begin{array}{l}\text { \% inhibition at } \\
\text { Extracts }\end{array}$ & \\
\hline Asc & $800 \mu \mathrm{g} / \mathrm{mL}$ & 57.85 \\
$\mathrm{AqE}$ & 19.44 & $511.64 \pm 8.2^{\mathrm{c}}$ \\
$\mathrm{MeE}$ & 62.28 & $149.14 \pm 6.1^{\mathrm{a}}$ \\
$\mathrm{EaE}$ & 23.45 & $410.61 \pm 12.3^{\mathrm{b}}$ \\
$\mathrm{nhE}$ & 9.43 & $1,025.82 \pm 18.4^{\mathrm{d}}$ \\
\hline
\end{tabular}

DPPH scavenging activity of the extracts was shown; $\mathrm{IC}_{50}$ values were the mean of triplicates $(n=3)$ with SD; mean values with ( $a, b, c, d)$ were significantly different with $p<0.001$;

Asc $=$ ascorbic acid; $\mathrm{MeE}=$ methanolic extract; $\mathrm{AqE}=$ aqueous extract; $\mathrm{EaE}=$ ethyl acetate extract; $\mathrm{nhE}=\mathrm{n}$-hexane extract
Fig. 3. Table 2 depicts the antioxidant activity of all the extracts.

\section{Reducing Power Activity}

Reducing power of ferric to ferrous ion was assessed for all the solvent extracts spectrophotometrically by recording the absorbance of Perl's Prussian blue complex. Fig. 4 represents the dose-responsive curves of all the extracts for reducing power. The higher absorbance was observed for $\mathrm{MeE}(1.15 \pm 0.03)$ at $200 \mu \mathrm{g} / \mathrm{mL}$. The decreasing order of reducing power was $\mathrm{Asc}>\mathrm{MeE}>\mathrm{EaE}>\mathrm{AqE}>\mathrm{nhE}$.

\section{In vitro Antidiabetic Activity}

\section{Glucose Uptake by Yeast Cell Assay}

$A$. reticulata leaf extracts of different concentrations were assessed for in vitro antidiabetic activity by glucose uptake assay using a yeast model. MeE exhibited potent activity (48.55\% at $500 \mu \mathrm{g} / \mathrm{mL}$ ) compared to the remaining extracts. A dose-dependant rise in the $\%$ of glucose

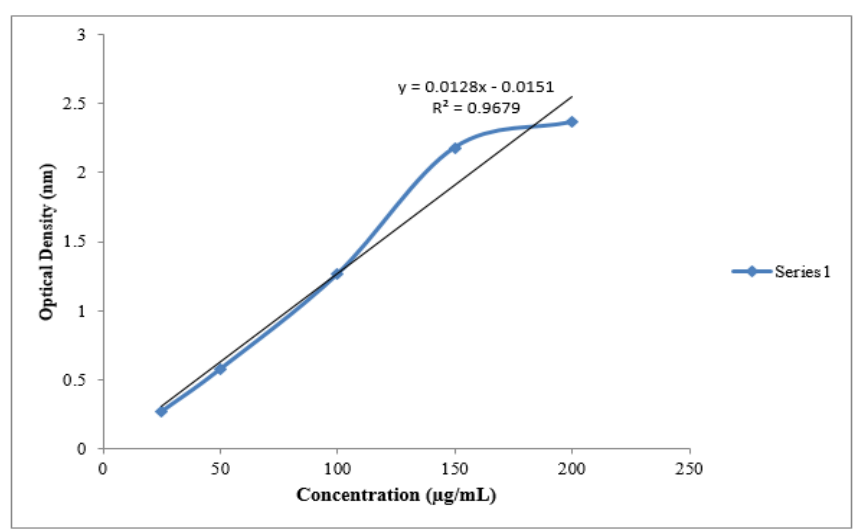

Fig. 3: Standard graph of ascorbic acid for total antioxidant activity represented the standard graph plotted for the ascorbic acid to evaluate the total antioxidant activity

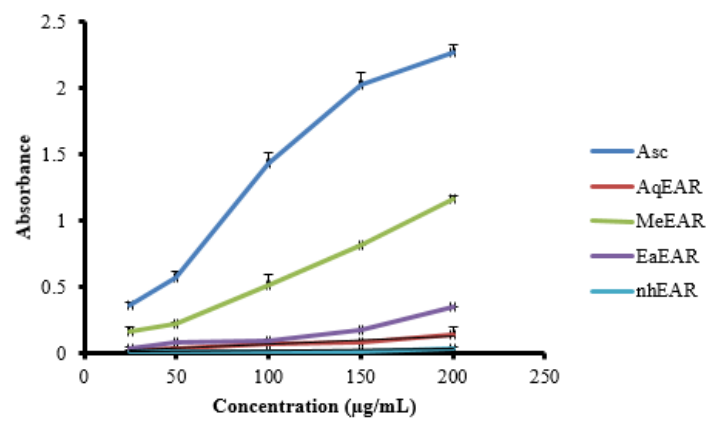

Fig. 4: Reducing power of $A$. reticulata leaf extracts along with standard Asc was shown; Asc = ascorbic acid; $\mathrm{AqE}=$ aqueous extract; $\mathrm{MeE}=$ methanolic extract; $\mathrm{EaE}$ = ethyl acetate extract; $\mathrm{nhE}=\mathrm{n}$-hexane extract

Table 2: Total antioxidant activity of all the four extracts of $A$. reticulata leaves

\begin{tabular}{lllll}
\hline & $A q E$ & $M e E$ & $E a E$ & $n h E$ \\
\hline Total antioxidant activity $(\mu \mathrm{g} / \mathrm{mL})$ & $42.3 \pm 0.66^{\mathrm{c}}$ & $164.72 \pm 2.63^{\mathrm{a}}$ & $92.5 \pm 6.5^{\mathrm{b}}$ & $10.34 \pm 0.57^{\mathrm{d}}$ \\
\hline All &
\end{tabular}

All the experimental values are mean of triplicates $(n=3)$ with $\pm S D$; the values sharing the different $(a, b, c, d)$ implies a significant difference among them $(\mathrm{p}<0.001)$; aqueous extract = AqE; methanolic extract = MeE; ethyl acetate extract = EaE; $n$-hexane extract = nhE 


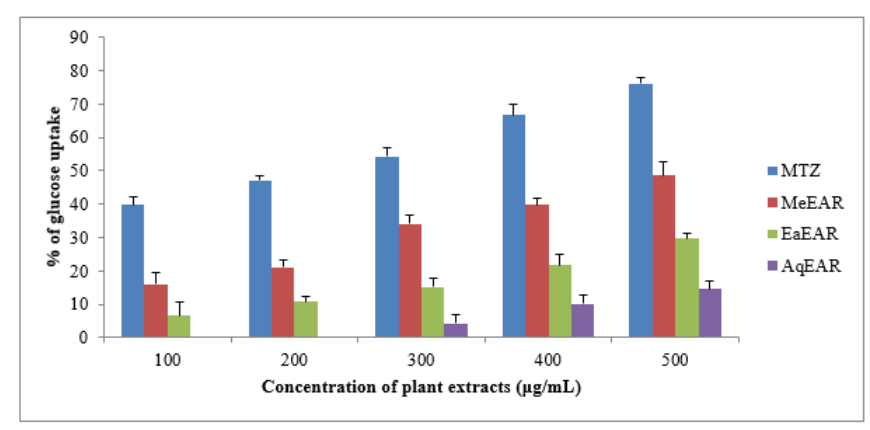

Fig. 5: In vitro antidiabetic activity of $A$. reticulata leaf extracts using a yeast cell model represented \% glucose uptake by yeast cells mediated by the $A$. reticulata L. plant extracts;

$\mathrm{MTZ}=$ metronidazole; $\mathrm{AqE}=$ aqueous extract; $\mathrm{MeE}=$ methanolic extract; $\mathrm{EaE}=$ ethyl acetate extract; $\mathrm{nhE}=\mathrm{n}$-hexane extract

uptake with increasing concentration $(100-500 \mu \mathrm{g} / \mathrm{mL})$ of $A$. reticulata leaf extracts was observed (Fig. 5). The increasing order of extracts in glucose uptake activity of extracts was MTZ $>$ MeE $>$ EaE $>$ AqE. The nhE did not exhibit any activity. The standard drug MTZ showed $76.08 \pm 1.86 \%$ at $500 \mu \mathrm{g} / \mathrm{mL}$.

\section{Discussion}

The present study included the determining of the antioxidant potential of $A$. reticulata leaf extracts as the oxidative stress is implicated with DM. ${ }^{[21]}$ In type2 DM, uncontrolled hyperglycemia appears to be the underlying cause of augment in plasma free radicals concentrations via different routes, such as, activation of the polyol pathway in cells, increased glycolysis, the formation of advanced glycation end products (AGEs), glucose autooxidation, which accelerates lipid peroxidation resulting in the accumulation of lipoxidation end products and other free radicals. The resultant formed oxidative products that damage the cells and tissues. ${ }^{[7]}$ Hence, the treatment, including the natural antioxidants, is one of the desirable pathways for the management of type 2 DM as the synthetic antioxidants are concerning with serious health issues. In this context, several medicinal plants are under screening for their various bioactivities. The existence of active constituents in the plants, such as, flavonoids, phenols, alkaloids, and tannins were responsible for various pharmacological properties. For instance, quercetin, a flavonoid with antioxidant property, removes free radicals, and thus, averts lipid peroxidation, metal ion chelation. ${ }^{[22]}$ Several reports suggested that tannins, terpenes, alkaloids possess pharmacological properties like antioxidant, antidiabetic, antipyretic, and anti-inflammatory properties. ${ }^{[23]}$

Four solvent extracts aqueous, methanol, ethyl acetate, and n-hexane was chosen for the study based on their polarity. The polarity of the solvents has a crucial role in solubilizing the active components of the plant extracts. ${ }^{[24]}$ The intricate nature of phytochemicals does not allow evaluating the antioxidant activity by a single method. ${ }^{[25]}$ Hence, three standard procedures were followed to evaluate the antioxidant activity of the extracts. Among many antioxidant assays, the DPPH method was known to be a stable method as the results of it are not affected by substrate polarity. The main principle behind the scavenging of the free radicals by the active constituents of plant extracts might be due to their hydrogen contributing ability to the free radicals to neutralize them, forming the stable compounds and thereby reducing their lethal effects. ${ }^{[25]}$ Here the free radical DPPH could be reduced upon the addition of antioxidant compounds that were present in the plant extracts, which leads to stable DPPH-H formation. Thus non-reactive stable forms of free radicals inhibit the chain initiation and break chain propagation, thus hinders the lipid peroxidation. ${ }^{[26]}$ Discoloration from purple to yellow was observed during reaction. The degree of discoloration visually indicates the antioxidant ability of plant extracts. ${ }^{[27]}$ Fig. 2 showed dose-dependent $\%$ of inhibition among four extracts. IC $_{50}$ of MeE was $149.14 \pm 6.1 \mu \mathrm{g} / \mathrm{mL}$ with highest DPPH scavenging activity followed by EaE, AqE, whereas, nhE showed minimum inhibition activity with IC ${ }_{50} 1,025.82 \pm 18.4 \mu \mathrm{g} / \mathrm{mL}$. IC $\mathrm{C}_{50}$ values of the extracts differ significantly from one another $(p<0.05)$. MeE exhibited high DPPH scavenging activity, which might be due to the solubility of more vital compounds in methanol solvent. Phosphomolybdenum method, to assess the total antioxidant activity was performed. Phosphate Mo (VI) reduced by the antioxidant compounds in the extract to form bluish-green colored complex phosphate Mo (V). The extracts' total antioxidant activity was represented in Table 2. Among the four extracts, MeE exhibited significant antioxidant activity $(164.72 \pm 2.63 \mu \mathrm{g} / \mathrm{mL})$. The electron transferability of a compound can be termed as its reducing power. The method is mostly preferred to evaluate the antioxidant property of dietary polyphenols. ${ }^{[1]}$ Reducing the ability of $A$. reticulata leaf extracts might exert its effect by scavenging the toxic metabolites decomposing the peroxides or preventing the chain initiation or breaks the free radical chain and thus, confers protection from the ROS. Of all extracts, MeE exhibited elevated antioxidant potential in comparison with other solvent extracts owing to the fact that methanol, being the efficient polar organic solvent, might solubilize more phenolic compounds ${ }^{[28]}$ and showed more antioxidant activity.

The $A$. reticulata leaves were also assayed for antidiabetic activity in vitro by the method-uptake of glucose using yeast cells, which is a lucrative parameter to assess the antidiabetic activity under in vitro conditions. The extent of glucose left after a particular time in the medium was considered to be a remarkable indicator of glucose uptake by yeast cells. ${ }^{[29]}$ The variation in the glucose uptake might be due to the extent of the solubility of various active constituents of plant extracts in the 
chosen solvents. Transporting of glucose across the cell membrane of yeast cells was mediated by the diffusion process with the intervention of stereospecific membrane carriers $^{[3,4]}$. The other mechanism that might involve in the glucose uptake process was the enhancement of cellular glucose metabolism ${ }^{[4]}$ by the $A$. reticulata extracts. The availability of active agents in plant extracts might facilitate the uptake of glucose across the cell membrane. Fig. 5 clearly showed that methanol extract of $A$. reticulata is more capable of effective glucose uptake by enhancing glucose utilization; thereby, it can control the blood glucose levels.

The present investigation could be concluded by stating that the methanol extract (MeE) of $A$. reticulata $\mathrm{L}$. leaves possesses high antioxidant potential. Our effort to determine the antidiabetic potential of $A$. reticulata $\mathrm{L}$. leaves using a yeast cell model conferred affirmative results. Further deep insights, such as, in vivo experiments on a rat model, the molecular mechanism involved in its pharmacological action, isolation of compounds, etc., on the potential of $A$. reticulata leaves in the alleviation of diabetes and its associated complications need to be demonstrated.

\section{REFERENCES}

1. Luximon-Ramma A, Bahorun T, Soobrattee MA, Aruoma OI. Antioxidant activities of phenolic, proanthocyanidin and flavonoid components in extracts of Cassia fistula. J Agric Food Chem. 2002;50(18):5042-5047.

2. Shettar AK, Sateesh MK, Kaliwal BB, Vedamurthya AB. In vitro antidiabetic activities and GC-MS phytochemical analysis of Ximenia americana extracts. South African Journal of Botany. 2017;111:202-211.

3. Mangesh B, Satish B. In vitro hypoglycemic effects of Albizzia lebbeck and Mucuna pruriens. Asian Pac J Trop Biomed. 2013;3(11):866-870.

4. Rehman G, Hamayun M, Iqbal A, Ul Islam S, Arshad S, Zaman K, et al. In vitro Antidiabetic Effects and Antioxidant Potential of Cassia nemophila Pods. Biomed Res Int. 2018;23:1824790.

5. Olamide EA, Funsho 00, Tan N, Zeng G. In vitro antioxidant activity, total phenolic and flavonoid contents of ethanol extract of stem and leaf of Grewia carpinifolia. Beni-Suef University Journal of Basic and Applied Sciences. 2017;6:10-14.

6. Chen K, Keaney JF Jr. Evolving concepts of oxidative stress and reactive oxygen species in cardiovascular disease. Curr Atheroscler Rep. 2012;14(5):476-483.

7. Chikezie PC, Okey AO, Agomuo CO. Oxidative stress in diabetes mellitus. Integr Obesity Diabetes. 2015;1(3):71-79.

8. Gao H, Cheng N, Zhou J, Wang B, Deng J, Cao W. Antioxidant activities and phenolic compounds of date plum persimmon (Diospyros lotus L.) fruits. J Food Sci Technol. 2014;51(5):950-956.

9. Patel DK, Kumar R, Prasad SK, Sairam K, Hemalatha S. Antidiabetic and in vitro antioxidant potential of Hybanthus enneaspermus (Linn) F. Muell in streptozotocin-induced diabetic rats. Asian Pac J Trop Biomed. 2011;1(4):316-322.

10. Tiwari BK, Kanti BP, Abidi AB, Syed IR. Markers of Oxidative Stress during Diabetes Mellitus. Journal of Biomarkers. 2013;8:378790.

11. Talukder FZ, Kousik AK, Riaz U, NusratJ, Md. Ashraful A. In vitro free radical scavenging and anti-hyperglycemic activities of Achyranthes aspera extract in alloxan-induced diabetic mice. Drug Discoveries \& Therapeutics. 2012;6(6):298-305.
12. Basiru OA, Oluwafemi AO, Oluwatosin A, Oluwatosin I, Isreal O, Adewale F, et al. Inhibitory effect on key enzymes relevant to acute type-2 diabetes and antioxidative activity of ethanolic extract of Artocarpus heterophyllus stem bark. Journal of Acute Disease. 2016;5(5):423-429.

13. Hossain MA, Shah MD, Gnanaraj C, Iqbal M. In vitro total phenolics, flavonoids contents and antioxidant activity of essential oil, various organic extracts from the leaves of tropical medicinal plant Tetrastigma from Sabah. Asian Pacific Journal of Tropical Medicine. 2011;717-721.

14. de Brum TF, Zadra M, Piana M, Boligon AA, Fröhlich JK, de Freitas $\mathrm{RB}$, et al. HPLC Analysis of Phenolics Compounds and Antioxidant Capacity of Leaves of Vitex megapotamica (Sprengel) Moldenke. Molecules. 2013;18:8342-8357.

15. Jamkhande PG, Wattamwar AS. Annona reticulata Linn. (Bullock's heart): Plant profile, phytochemistry and pharmacological properties. J Tradit Complement Med. 2015;5(3):144-152.

16. Rajsekhar PB, Arvind Bharani RS, Maya R, Jini Angel K, Sharadha PVR. The "Wonder Plant" Kalanchoe pinnata (Linn.) Pers.: A Review. Journal of Applied Pharmaceutical Science. 2016;6(03):151-158.

17. Kadali VN, Sandeep BV. Anti-hyperglycemic plants used by the traditional healer of west Godavari District, Andhra Pradesh, India. Int J Pharmacognosy. 2015; 2(9):473-77.

18. Nasri H, Shirzad H, Baradaran A, Rafieian-kopaei M. Antioxidant plants and diabetes mellitus. Journal of Research in Medical Sciences. 2015;(5):491-502.

19. Nabi SA, Kasetti RB, Sirasanagandla S, Tilak TK, Kumar MV, Rao CA. Antidiabetic and antihyperlipidemic activity of Piper longum root aqueous extract in STZ induced diabetic rats. BMC Complementary and Alternative Medicine. 2013;13(1):37.

20. Srinivasan S, Wankupar W, Sheeladevi R, Ravindran R. Free radical scavenging potential and HPTLC analysis of Indigofera tinctoria Linn. (Fabaceae). Journal of Pharmaceutical Analysis. 2016; 125-131.

21. Kazeem MI, Ashafa AO. In-vitro antioxidant and antidiabetic potentials of Dianthus basuticus Burtt Davy whole plant extracts. Journal of Herbal Medicine. 2015;5(3):158-164.

22. Kooti W, Farokhipour M, Asadzadeh Z, Ashtary-Larky D, Asadi-Samani M. The role of medicinal plants in the treatment of diabetes: A systematic review. Electron Physician. 2016;8(1): 1832-1842.

23. Foluso OO, Godfrey EZ, Andy RO. Phytochmical constituents and antioxidant potential of crude extracts from Lippia javanica (Burm.f.) Spreng leaves. Pharmacognosy Journal. 2019;11(4):803-807.

24. Faten M, Hanen F, Riadh K, Chedly A. Total phenolic, flavonoid and tannin contents and antioxidant and antimicrobial activities of organic extracts of shoots of the plant Limonium delicatulum. Journal of Taibah University for Science. 2018;8:216-224.

25. Gangwar M, Gautam MK, Sharma AK, Tripathi YB, Goel RK, Nath G. Antioxidant capacity and radical scavenging effect of polyphenol rich Mallotus philippenensis fruit extract on human erythrocytes: an in vitro study. The Scientific World Journal. 2014;279451.

26. Apati P, Szentmihalyi K, Kristo ST, Papp I, Vinkler P, Szoke E, et al. Herbal remedies of Solidago, correlation of phytochemical characteristics and antioxidative properties. J Pharm Biomed Anal. 2003;32:1045-1053.

27. Islam E, Islam R, Rahman AA, Alam AK, Khondkar P, Rashid M, et al. Estimation of total phenol and in vitro antioxidant activity of Albizia procera leaves. BMC research notes. 2013;6(1):121.

28. El-Chaghaby GA, Ahmad AF, Ramis ES. Evaluation of the antioxidant and antibacterial properties of various solvents extracts of Annona squamosa L. leaves. Arabian Journal of Chemistry. 2014;7(2): 227-233.

29. Cherbal A, Kebieche M, Yilmaz EM, Aydoğmuş Z, Benzaouia L, Benguessoum $\mathrm{M}$, et al. Antidiabetic and hypolipidemic activities of Algerian Pistachia lentiscus L. leaves extract in alloxan-induced diabetic rats. South African Journal of Botany. 2017;108:157-162.

HOW TO CITE THIS ARTICLE: Pulivarthi V, Josthna P, Naidu CV. In vitro antidiabetic activity by glucose uptake of yeast cell assay and antioxidant potential of Annona Reticulata L. leaf extracts. Int. J. Pharm. Sci. Drug Res. 2020;12(3):208-213. DOI: 10.25004/IJPSDR.2020.120301 